\title{
Urgency and Necessity on Adjustment of China's Current Agricultural Structure Based on the Stability and Developmental Trend Analyses of Pork Yield in China
}

\author{
Cangyu Jin, Huilong Lin* \\ State Key Laboratory of Grassland Agro-Ecosystems, College of Pastoral Agriculture Science and Technology, \\ Lanzhou University, Lanzhou, China \\ Email: ${ }^{*}$ linhuilong@Izu.edu.cn
}

Received 18 June 2014

\begin{abstract}
With the development of economy, meat gradually plays an important role in Chinese people's dietary pattern. As the most direct reflection of agricultural system, food system has always been the main output of agricultural system, and pork has occupied an important position in Chinese food system. We attempts to find the systematical disorder of current agricultural system by analyzing the meat output of the agricultural system. H-P Filter and Grey Prediction GM(1,1) Model was adopted to explore the inner rules between pork production and agricultural system in China. The results indicated that pork consumption ratio in Chinese urban residents' dietary pattern constantly kept about $6 \%$, the growth potential of grain yield is limited while the growth potential of pork yield is increased in China. By Grey Prediction GM(1,1) Model, we predicted the pork yield would reach $59.07 \mathrm{Mt}$ in 2020, 110.25 Mt in 2060, 205.78 Mt in 2100, the demand of feed would reach 177.22 Mt in 2020, 330.75 Mt in 2060, 617.34 Mt in 2100. In China, agricultural system is traditional "pork-grain" mode, feed has been one of the biggest section that consumed grain. The present "pork-grain" agricultural system cannot meet the huge demand of grain from feed, adjusting the agricultural structure is imperative. Reforming the current agricultural system into grassland agricultural system which takes the beef and mutton as predominates would be a good choice for China in the future.
\end{abstract}

\section{Keywords}

Pork Yield, H-P Filter, Grey Prediction GM(1,1) Model, Grassland Agriculture, Food Security, China

\section{Introduction}

China's growing population has made the grain problem prominent. People's dietary pattern is the corresponding system of grain problem. Today, there are mainly four kinds dietary pattern around the world. 1) Developed

\footnotetext{
"Corresponding author.
}

How to cite this paper: Jin, C.Y. and Lin, H.L. (2014) Urgency and Necessity on Adjustment of China's Current Agricultural Structure Based on the Stability and Developmental Trend Analyses of Pork Yield in China. Journal of Agricultural Chemistry and Environment, 3, 16-23. http://dx.doi.org/10.4236/jacen.2014.33B003 
country's pattern, it is also called the mode of rich, animal foodstuff is the main component. Annual consumption of animal foodstuff per capita is $270 \mathrm{~kg}$, direct consumption of grain only $60-70 \mathrm{~kg}$. 2) Developing country's pattern, the main part of it is plant foodstuff. Annual grain and potato consumption per capita run up to 200 $\mathrm{kg}$, the consumption of meat, eggs and fish only $5 \mathrm{~kg}$, milk consumption is few in some developing countries. 3) Japan pattern, it is also called nutrient pattern. It not only holds the characteristics of traditional oriental diet, but also absorbs the advantages of the European and American diet, combines with its prosperous economy, annual grain consumption per capita is $110 \mathrm{~kg}$, animal foodstuff is about $135 \mathrm{~kg}$. 4) Mediterranean pattern, it is a peculiar type of Mediterranean residents. The prominent point is the intake of saturated fat is low, and high intakes of polyunsaturated fats [1]. The formation of a fixed dietary pattern, there must have a strong and stable agricultural system as backup. Every kind of dietary pattern correspondences with a relative agricultural system. At present, dietary pattern of our country's residents gradually turns to developed country's mode or Japan mode from developing country's model, this change is irresistible. Meat consumption has been expanded, annual main meat (include pork, beef and mutton) consumption per capita of rural residents reached $16.4 \mathrm{~kg}$ in 2012 from $13.2 \mathrm{~kg}$ in 1998, annual meat (include pork, beef and mutton) consumption per capita of urban residents reached $24.96 \mathrm{~kg}$ in 2012 from $13.2 \mathrm{~kg}$ in 2002 [2]. But, no matter the meat consumption in rural or urban, it is far less than developed countries' $270 \mathrm{~kg}$ per capita and Japan mode's $135 \mathrm{~kg}$ per capita of animal foodstuff consumption. As the living standard leveled up, with the development of economy, our country is in a transitional period of dietary pattern upgrading. The essence of agricultural system is food system, its basic mission is food production. Meat is an important component of food, has a higher request of agricultural system's comprehensive integration, to some extent, it is a reflection of agricultural system structure. Recently, the study on large scale time series by H-P filter is increasing, mainly concentrated on cycle fluctuation. Ye (2012) [3] analyzed the increase and stable of grain yield from Chinese economic reform in 1978. Gao (2009) [4], on the basis of H-P filter, listed the factors that influenced the cycle and trend of our country's grain yield. However, there is few discussion in meat yield by H-P filter in China.

In this paper, pork yield and grain yield was chosen to be analyzed whether the agricultural system and dietary pattern was matching, whether the agricultural system can keep the same pace with the dietary pattern upgrading or not. All of these came down to the analysis of time series. The purpose of this paper is to: 1) find the interaction between agricultural system and pork yield; 2) through the comparison between grain yield and pork yield, discover sections that agricultural system deviated the dietary pattern upgrading; 3) provide suggestions to cater to the upgrading and direction of agricultural system adjusting.

\section{Materials and Methods}

\subsection{Data Acquisition}

The statistics of pork consumption, pork yield from 1980 to 2012, grain yield from 1978 to 2012 were obtained from the National Bureau of Statistics of China (http://www.stats.gov.cn/).

\subsection{Methods}

Pork consumption ratio in Chinese urban and rural residents' dietary pattern was calculated under Excel 2007.

In order to observe the developmental trend and cycle of grain yield and pork yield, H-P filter [5] (1980), a method that separate trend component and cycle component from a large scale time series [6], was chosen and evaluated under Eviews 6.0 environment.

Grey Prediction GM(1,1) Model was applied to predict the pork yield. Grey Prediction GM(1,1) Model was widely spread in predicting series that has few original data and predicted background appeared developmental trend [7].

Prediction of pork yield by Grey Prediction GM(1,1) Model, below steps should be followed:

Constructed original data series $X^{(0)}$,

$$
X^{(0)}=\left(x^{(0)}(1), x^{(0)}(2), x^{(0)}(3), x^{(0)}(4), x^{(0)}(5), \ldots, x^{(0)}(\mathrm{n})\right)
$$

(1) Accumulated $X^{(0)}$ once, got $X^{(1)}$

(2) Did smooth test for $X^{(0)}$,

$$
\rho(k)=\frac{x^{(0)}(k)}{x^{(1)}(k-1)}
$$


(3) Examined whether $X^{(1)}$ had quasi exponential rule or not. From

$$
\sigma^{(1)}(k)=\frac{x^{(1)}(k)}{x^{(1)}(k-1)}=1+\rho(k)
$$

(4) Produced neighboring value for $X^{(1)}$, got $Z^{(1)}$, therefore,

$$
B=\left[\begin{array}{cc}
-z^{(1)}(2) & 1 \\
-z^{(1)}(3) & 1 \\
\cdots & 1 \\
-z^{1}(n) & 1
\end{array}\right], Y=\left[\begin{array}{l}
x^{(0)}(2) \\
x^{(0)}(3) \\
x^{(0)}(4) \\
\cdots \cdots \\
x^{(0)}(\mathrm{n})
\end{array}\right]
$$

(5) Least square estimation for parameter series $\hat{\alpha}=[a, b]^{\mathrm{T}}$, got

$$
\hat{\alpha}=\left(B^{\mathrm{T}} B\right)^{-1} B^{\mathrm{T}} Y
$$

(6) Confirmed model

$$
\frac{\mathrm{d} x^{(1)}}{\mathrm{d} t}-a x^{(1)}=u
$$

and time response series,

$$
\hat{x}^{(1)}(k+1)=\left(x^{(0)}(1)-\frac{b}{a}\right) \mathrm{e}^{-a k}+\frac{b}{a}
$$

(7) Evaluated the analog value of $X^{(1)}$

$$
\hat{X}^{(1)}=\left(\hat{X}^{(1)}(1), \hat{X}^{(1)}(2), \ldots, \hat{x}^{(1)}(n)\right)
$$

(8) Reduced and evaluated the analog value of $X^{(0)}$. From

$$
\hat{x}^{(0)}(k+1)=a^{(1)} \hat{x}^{(1)}(k+1)=\hat{x}^{(1)}(k+1)-\hat{x}^{(1)}(k)
$$

got

$$
\hat{X}^{(0)}=\left(\hat{x}^{(0)}(1), \hat{x}^{(0)}(2), \ldots, \hat{x}^{(0)}(n)\right)
$$

(9) Error detection.

(10) Predicted $\hat{x}^{(0)}(k+1)$.

\section{Results}

\subsection{Pork Consumption Ratio in Chinese Urban and Rural Residents' Dietary Pattern}

Pork consumption ratio in Chinese urban residents' dietary pattern constantly kept about 6\%. Pork consumption still occupied a small share in urban residents' dietary pattern. It was the same in rural residents' dietary pattern and even less. From 3.5\% in 2002 to 4.8\% in 2012, the annual average growth rate was approximately $0.12 \%$

(Figure 1).

Pork yield in China was soared in the last 32 years, the trend line appeared almost a line and the growth potential appeared increased compared with 1980s and 1990s. Divided the cyclical component of H-P filter into three cycles from crest to crest during 1978 and 2012, neglecting the fluctuation which is shorter than 5 years. 1) From 1980 to 1995, the span was 15 years, has a 4 million tons' crest. 2) From 1995 to 2005, t he span was 10 years, with a crest of 4 million tons and a trough of -2.5 million tons. 3) From 2005 to 2012, spanning 7 years, with a trough of -3.5 million tons in 2004 . Three cycles has a intensify trough trend, this made it clear that the growth potential increased in the near future (Figure 2).

\subsection{H-P Filter of Grain Yield during 1978-2012 in China}

The trend of grain yield in China is increase, but the growth potential of it is slow down gradually. From Figure 3, it showed the increase trend (red line) and cycle (green line) of grain yield during 1978-2012. As for cyclical 


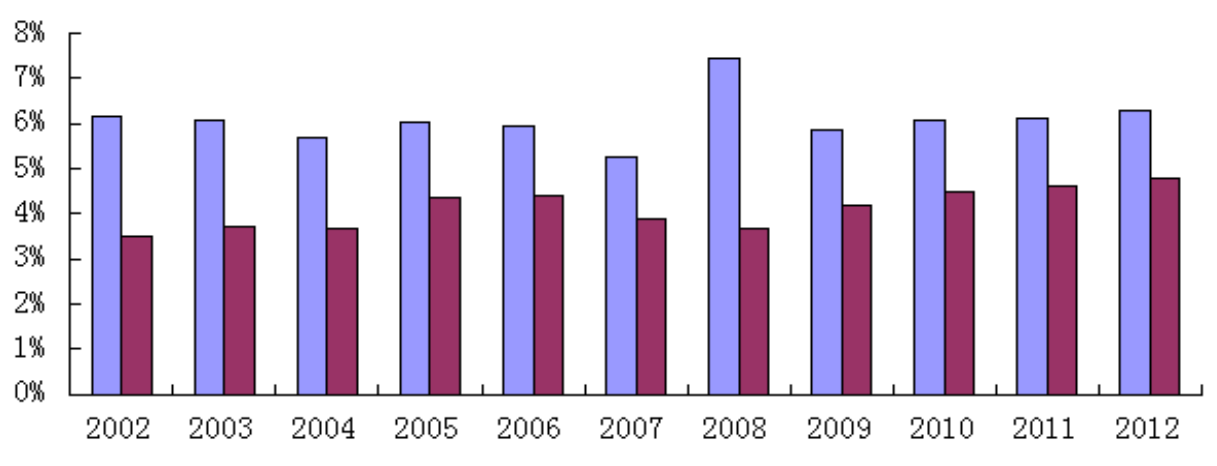

$\square$ Urban $\square$ Rural

Figure 1. Pork consumption ratio in Chinese urban and rural residents' dietary pattern during 2002-2012.

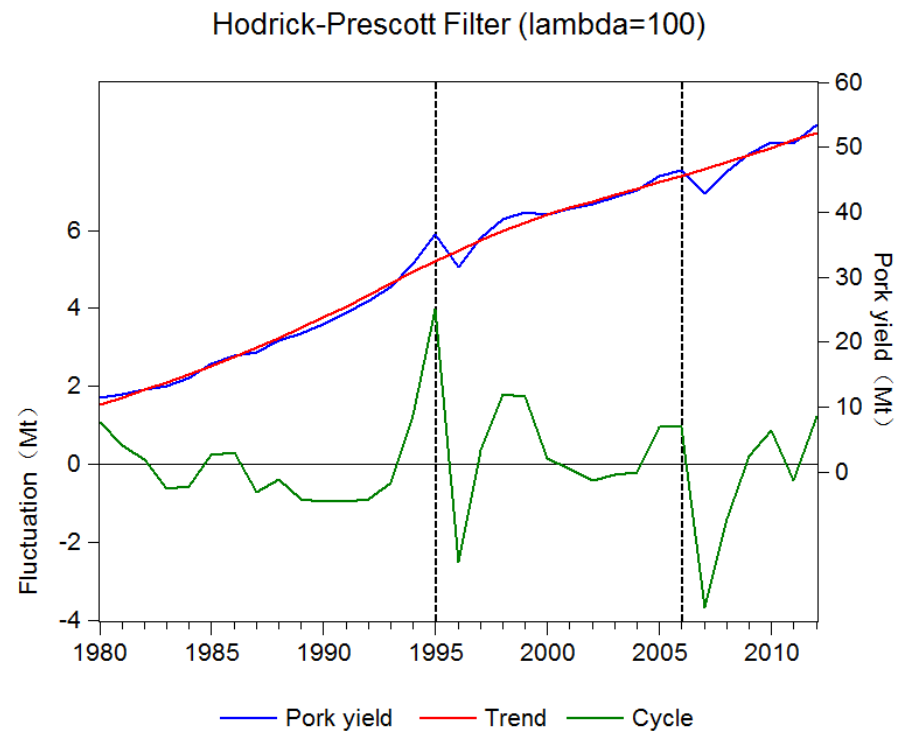

Figure 2. H-P filter of pork yield during 1980-2012 in China.

Hodrick-Prescott Filter (lambda=100)

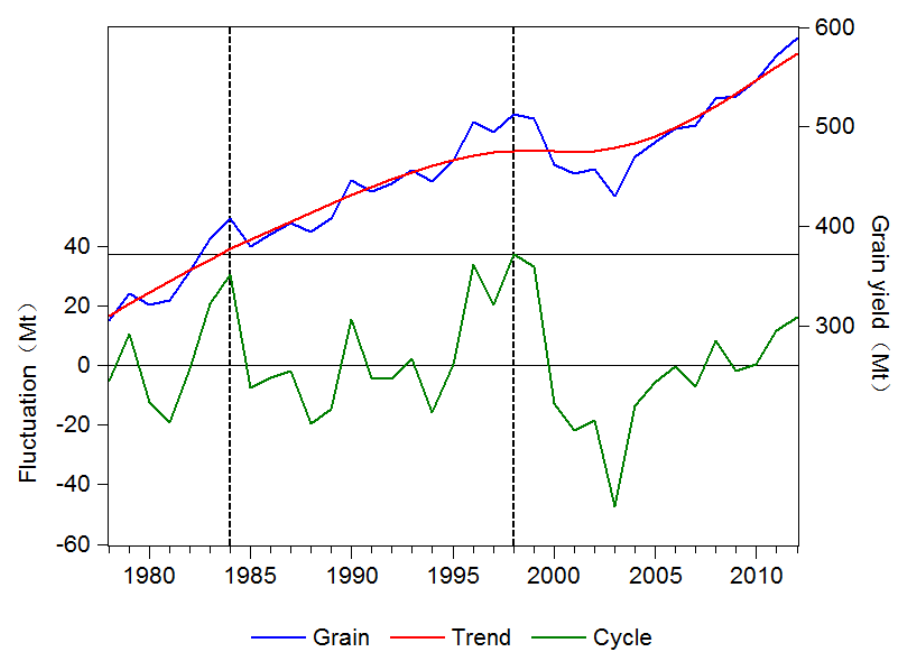

Figure 3. H-P filter of grain yield during 1978-2012 in China. 
component of H-P filter, the grain yield cycle was divided into three cycles from crest to crest during1978 and 2012, neglecting the fluctuation which is shorter than 5 years. 1) From 1978 to 1984, the span was 6 years, has a 27 million tons' crest. 2) From 1984 to 1998, the span was 14 years, with a crest of 21 million tons in 1984 and 37 million tons in 1998. 3) From 2000 to 2012, spanning 12 years, the crest was 37million tons in 1998. Compared with the waves in the first and second cycle, after 2004, the cycle obviously had a decreasing tendency of fluctuation, it showed a slowdown in growth speed of grain yield. This indicated that the growth potential of grain yield is limited in China.

\subsection{Pork Yield Predicted by Grey Prediction GM(1,1) Model}

Constructed original data series $X^{(0)}$ by data from Table 1, namely,

$$
X^{(0)}=(49.02,49.78,50.56,51.35,52.16)
$$

(1) Accumulated $X^{(0)}$ once, got

$$
X^{(1)}=(49.02,98.80,149.35,200.71,252.87)
$$

(2) Did smooth test for $X^{(0)}$, from $\rho(k)$ got,

$$
\rho(3) \approx 0.51, \rho(4) \approx 0.34<0.5, \rho(5) \approx 0.26<0.5
$$

when $k>3$, quasi smooth condition was satisfied.

(3) Examined whether $X^{(1)}$ had quasi exponential rule or not. From $\sigma^{(1)}(k)$ got,

$$
\sigma^{(1)}(3) \approx 1.51, \sigma^{(1)}(4) \approx 1.34, \sigma^{(1)}(5) \approx 1.26,
$$

when $k>3, \sigma^{(1)}(k)=\in[1,1.5], \delta<0.5$, quasi exponential rule was satisfied, therefore, Grey Prediction $\mathrm{GM}(1,1)$ model can be constructed for $X^{(1)}$.

(4) Produced neighboring value for $X^{(1)}$, got

$$
Z^{(1)}=(73.91,124.1,175.02,226.8)
$$

therefore,

$$
B=\left[\begin{array}{cc}
-73.91 & 1 \\
-124.1 & 1 \\
-175.02 & 1 \\
-226.8 & 1
\end{array}\right], Y=\left[\begin{array}{l}
49.78 \\
50.56 \\
51.35 \\
52.16
\end{array}\right]
$$

(5) Least square estimation for parameter series $\hat{\alpha}=[a, b]^{\mathrm{T}}$, got

$$
\hat{\alpha}=\left(B^{\mathrm{T}} B\right)^{-1} B^{\mathrm{T}} Y=\left[\begin{array}{c}
-0.0156 \\
48.62
\end{array}\right]
$$

(6) Confirmed model $\frac{\mathrm{d} x^{(1)}}{\mathrm{d} t}-0.0156 x^{(1)}=48.62$ and time response series,

$$
\hat{x}^{(1)}(k+1)=\left(x^{(0)}(1)-\frac{b}{a}\right) e^{-a k}+\frac{b}{a}=3164.85 e^{0.0156 k}-3115.83
$$

(7) Evaluated the analog value of $X^{(1)}$

$$
\hat{X}^{(1)}=\left(\hat{X}^{(1)}(1), \hat{X}^{(1)}(2), \hat{x}^{(1)}(3), \hat{x}^{(1)}(4), \hat{X}^{(1)}(5)\right)=(49.02,98.78,149.32,200.66,252.80)
$$

(8) Reduced and evaluated the analog value of $X^{(0)}$. from

Table 1. Pork yield in China during 2008-2012 (unit: Mt).

\begin{tabular}{cccccc}
\hline Year & 2008 & 2009 & 2010 & 2011 & 2012 \\
\hline Yield & 49.02 & 49.777 & 50.556 & 51.353 & 52.162 \\
\hline
\end{tabular}




$$
\hat{\chi}^{(0)}(k+1)=a^{(1)} \hat{\chi}^{(1)}(k+1)=\hat{x}^{(1)}(k+1)-\hat{\chi}^{(1)}(k),
$$

got

$$
\hat{X}^{(0)}=\left(\hat{x}^{(0)}(1), \hat{x}^{(0)}(2), \hat{x}^{(0)}(3), \hat{x}^{(0)}(4), \hat{x}^{(0)}(5)\right)=(49.02,49.76,50.54,51.34,52.14)
$$

(9) Error detection. Evaluated the sum of squares of residues from Table 2.

(10) Predicted $\hat{x}^{(0)}(k+1)$ (Table 3).

\subsection{The Derivate Demand of Feed by the Predicted Pork Yield}

Pig is a kind of grain-consumption animal. The increased yield of pork would converted into the increased demand of feed. The convert ratio between pork and feed is 1:3, namely every $1 \mathrm{~kg}$ pork need $3 \mathrm{~kg}$ feed's "food unit" (grain and forage grass were included) [8]. The demand of feed can be estimated. It can be seen that the demand of feed will reach 177.22 Mt in 2020, $330.75 \mathrm{Mt}$ in 2060, 617.34 Mt in 2100. The yield of grain under increasing pressure (Table 4).

\section{Discussion}

\section{1. "Pork-Grain" Agriculture Was a Real Reflect of Chinese Agricultural System}

Traditional agricultural mode still widely existed in rural areas in China. The output of our agricultural system mainly was grain and meat. Meat usually transferred from grain for the feed of pig always has been grain. The traditional meat in China is pork.

Table 2. Error detection (unit: Mt).

\begin{tabular}{ccccc}
\hline Number & $\begin{array}{c}\text { Actual data } \\
x^{(0)}(k)\end{array}$ & $\begin{array}{c}\text { Analogy data } \\
\hat{x}^{(0)}(k)\end{array}$ & $\begin{array}{c}\text { Residues } \\
\varepsilon(k)=x^{(0)}(k)-\hat{x}^{(0)}(k)\end{array}$ & $\begin{array}{c}\text { Relative deviation } \\
\Delta_{k}=\frac{|\varepsilon(k)|}{\chi^{(0)}(k)}\end{array}$ \\
\hline 2 & 49.78 & 49.76 & 0.02 & $0.040 \%$ \\
3 & 50.56 & 50.54 & 0.02 & $0.040 \%$ \\
4 & 51.35 & 51.34 & 0.01 & $0.019 \%$ \\
5 & 52.16 & 52.14 & 0.02 & $0.038 \%$ \\
& & & Average relative deviation & $0.034 \%$ \\
\hline
\end{tabular}

Table 3. Results of Pork yield from Grey Prediction GM(1,1) model during 2013-2100 in China (unit: Mt).

\begin{tabular}{ccccccccc}
\hline Year & 2013 & 2014 & 2015 & 2016 & 2017 & 2018 & 2019 & 2020 \\
\hline Yield & 52.96 & 53.80 & 54.64 & 55.50 & 56.37 & 57.26 & 58.16 & 59.07 \\
Year & 2025 & 2030 & 2035 & 2040 & 2045 & 2050 & 2055 & 2060 \\
Yield & 63.87 & 69.05 & 74.65 & 80.7 & 87.25 & 94.33 & 101.98 & 110.25 \\
Year & 2065 & 2070 & 2075 & 2080 & 2085 & 2090 & 2095 & 2100 \\
Yield & 119.2 & 128.87 & 139.32 & 150.62 & 162.84 & 176.05 & 190.34 & 205.78 \\
\hline
\end{tabular}

Table 4. The demand of feed during 2013 and 2020 in China (unit: Mt).

\begin{tabular}{ccccccccc}
\hline Year & 2013 & 2014 & 2015 & 2016 & 2017 & 2018 & 2019 & 2020 \\
\hline Yield & 158.89 & 161.39 & 163.92 & 166.50 & 169.12 & 171.78 & 174.48 & 177.22 \\
Year & 2025 & 2030 & 2035 & 2040 & 2045 & 2050 & 2055 & 2060 \\
Yield & 191.61 & 207.15 & 223.95 & 242.1 & 261.75 & 282.99 & 305.94 & 330.75 \\
Year & 2065 & 2070 & 2075 & 2080 & 2085 & 2090 & 2095 & 2100 \\
Yield & 357.6 & 386.61 & 417.96 & 451.86 & 488.52 & 528.15 & 571.02 & 617.34 \\
\hline
\end{tabular}




\subsection{The Grain Crisis of Agricultural System}

In China, pork consumption plays an important role in meat consumption, the ratio is over 60\%. Pig is grain consumption animal, the increase in pork yield inevitably induced the increase demand of grain. There existed an opposite phenomenon, the growth potential of pork yield appeared increase but the growth potential of grain yield is limited in the near future. In 2020, the feed demand will reach 177.22 Mt, 617.34 Mt in 2100, it is impossible to complete the task only by our traditional agricultural system. The grain gap brought by pork yield will inevitably become a problem of food security in China. The unreasonable structure of agricultural system is the main reason that pork plays a key role in Chinese dietary pattern. "Pork-grain” Agriculture will not support the huge demand of grain in the near future. Agricultural system has no choice but undertook this increased pressure. Meanwhile, this kind pressure pushes the upgrading of dietary pattern and urges people to consider how to transform the existed agricultural system. Decreases the demand of pork, drives “pig-grain” agricultural system to grassland agricultural system, increases the demand of beef and mutton is a good choice.

\subsection{Grassland Agriculture Is the Direction of Agricultural System in China}

Ren Jizhou (2005) [9] considered Chinese traditional agricultural system “take grain as the key link” existed inborn handicaps, neglected plant-eating animal husbandry was the possible reason. The essence of grassland agriculture was the combination of grassland, farmland and forest, plant production and animal production, material production and spirit producing, product producing and circulation producing. It was a multilevel modern comprehensive agricultural system, broke the mental set of "take grain as the key link" [10]. The implementation of grassland agriculture can save feed grain for the food products from grassland are milk and meat from ruminant animals, which could fed on forage grass [11]. It also can provide a large number of high-quality animal food which plays an important role in healthy dietary pattern and developed country's dietary pattern. This will speed up our country's dietary pattern upgrading. In China, grassland accounts for about $41.7 \%$ of the total land area [12]. Making full use of the $41.7 \%$ land area, adjusting the agricultural structure, will have a significant meaning for China’s food safety and dietary pattern upgrading.

\section{Acknowledgements}

The research was supported by the key consultative project "Ecological security of grassland and food security in China” by Chinese Academy of Engineering (2012-ZD-7) and Program for Changjiang Scholars and Innovative Research Team in University (IRT13019).

\section{References}

[1] http://baike.baidu.com/link?url=DGQOm3lIGdtKvnesRXsrIEfI4YmGRoOtvcJ94evP0ObWKv3VaykFJKG6yjL9eK-b

[2] National Bureau of Statistics of China. http://www.stats.gov.cn/

[3] Ye, M.-H. (2012) Has Chinese Crop Production Increased Stably? Based on Crop Production H-P Filter in Major Crop Producing Areas: 1978-2009. Finance and Trade Research.

[4] Gao, F. (2009) The Volatility and Growth Trend of Grain Production in China: Empirical Study Based on H-P Filtering Method. Economist.

[5] Hodrick, R.J. and Prescott, E.C. (1980) Post-War U.S. Business Cycles: An Empirical Investigation. Working Paper, Carnegie-Mellon University.

[6] Gao, T.M. (2009) Econometric Analysis and Modeling. Reviews Application and Cases. Tsinghua University Press, Beijing, 40-41.

[7] Chen, M.Y. and Yang, J.G. (2009) Based on Gray GM(1,1) Handan Urbanization Level Forecast. Mathematics in Practice and Theory.

[8] Ren, J.Z. (2013) Chinese Traditional Agricultural System Have to Change-The Worries of Nine Successive Increase of Grain Yield. Acta Parataculture Sinica.

[9] Ren, J.Z. (2005) On Developmental Process of Chinese Agrarian Culture and Evolution of Its Agriculture Priority Ideas. Agricultural History of China.

[10] Ren, J.Z. (2002) Establishment of an Agro-Grassland Systems for Grain Storage-A Thought on Restructure of Agricultural Frame Work in Western China. Acta Parataculture Sinica. 
[11] Lin, H.L., Li, R.C., Jin, C.Y., Wang, H., Wei, M.H. and Ren, J.Z. (2014) China’s New Problems of Food Security Revealed by the Food Equivalent Unit .Frontiers of Agricultural Science and Engineering, 1, 69-76.

[12] Lin, H.L. (2007) Pastoral Agriculture Science Goes through Structural Description Stage to Precise Development Stage. Pratacultural Science. 